NASZA DERMATOLOGIA Online OUR DERMATOLOGY Online

Source of Support: Nil

Competing Interests: None

\section{XERODERMA PIGMENTOSUM: A BANE IN DEVELOPING COUNTRY - BRIEF REPORT}

\author{
Hari Kishan Kumar Yadalla, Syeda Juwariya \\ Department of Dermatology, Raja Rajeswari Medical College \& Hospital, Kambipu- \\ ra, Mysore Road, Bangalore, India
}

Corresponding author: Assoc. Prof. Hari Kishan Kumar Yadalla drkishanyadalla@rediffmail.com

\begin{abstract}
Xeroderma pigmentosum (XP) is a rare autosomal recessive disorder characterized by photosensitivity, cutaneous pigmentary changes, premature skin ageing, and the development of various cutaneous and internal malignancies at an early age. We present this case of a 10 yearold girl in a developing country like India, with significant corneal scarring and multiple cutaneous skin lesions in sun-exposed areas. Developmental delay had been present since 3 months of age, with these clinical features it was consistent with Xeroderma Pigmentosum. We highlight the difficulties encountered due to the lack of diagnostic and treatment modalities for this child, and offer a brief review of XP, including emerging treatments.
\end{abstract}

Key words: Xeroderma Pigmentosum; Developing countries; Cutaneous lesions

\section{Introduction}

Xeroderma pigmentosum is a rare, genetically heterogeneous, autosomal recessive disorder characterized by photosensitivity, cutaneous pigmentary changes, premature skin ageing, and the development of various cutaneous and internal malignancies at an early age. The basic defect underlying the clinical manifestations is a nucleotide excision repair (NER) defect leading to a defective repair of DNA damaged by ultra violet (UV) radiation [1]. XP is characterized by clinical and cellular hypersensitivity to UV radiation manifesting as intolerance of skin and eyes to light. The skin lesions are comprised of freckles on limbs and face with a dry skin covered with a mixture of mottled, hypopigmented and hyperpigmented, atrophic rounded

and oval macules, giving the entire skin a checkered appearance associated with a generalized actinic keratoses, manifesting on black skin as palpable, rough, blackish spots covered with adherent scales $[2,4]$. These skin lesions cover both the sun exposed and covered areas. The skin later develops cutaneous malignancies. Ocular changes include photophobia, ocular pigmentary changes, conjunctivitis, corneal keratitis, ulcers, blindness, and malignancies. The diagnosis of XP can be established with studies performed in specialized laboratories. These studies include cellular hypersensitivity to UV radiation and chromosomal breakage studies, complementation studies, and gene sequencing to identify the specific gene complementation group [1-4]. The patient, in our case report, presented with characteristic atrophic, freckled and lentigo skin changes, subnormal intelligence with developmental delay and blurred vision along with the highlighting aspect of delay in medical diagnosis and appropriate treatment.

\section{Case Report}

A 10 year-old girl presented to our out-patient department with parental concern regarding progressive skin and ocular lesions. The history was unusual, since the age of 3 months the patient had suffered with persistent developmental delay as well as the appearance of multiple pigmented papular lesions on her face, neck, and forearms. Over time these lesions had enlarged and become progressively more numerous and raised, although were confined to sun-exposed areas. In the last year her mother had noted gradually enlarging corneal lesions bilaterally.

Following normal vaginal delivery at home with no prenatal care, and the development had been limited with low intelligence. Although a generally happy and smiling child. She has 1 normal sibling, and there was no family history or other past medical history of note. The mother denied any consanguinity in the patient's recent lineage.

On examination the patient was smiling and playful, and appeared well-nourished. 
There were also numerous hyperpigmented lentigos and freckles with xerosis limited to sun-exposed sites. Few Hyperkeratotic lesions were present on the cheeks and nose with some induration suggestive of actinic keratosis. Marked corneal scarring was evident bilaterally. She had diffuse hyperpigmented lentigos and freckles mixed with hypopigmented macules over the extremeties. (Figs 1 - 2). There was no evidence of anaemia or overt signs of vitamin deficiencies such as rickets, and the mother and siblings appeared well nourished.

Physical examination of the heart, lungs and abdomen was unremarkable. Given the cutaneous, neuro-developmental delay and ocular features a presumptive diagnosis of Xeroderma Pigmentosum was made. A skin biopsy was performed

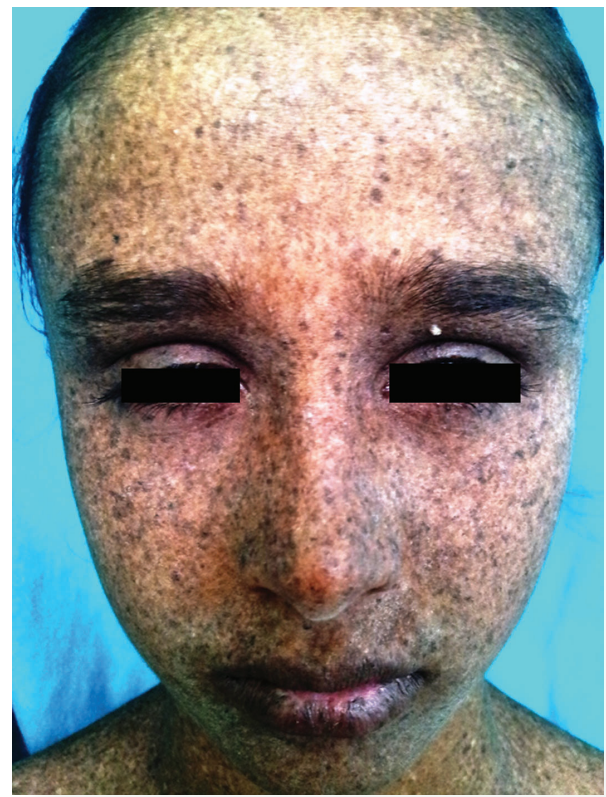

Figure 1. Frontal image of face, showing numerous hyper-pigmented lentigos and freckles with xerosis of the face with diffuse hyperkeratotic lesions.

Marked corneal scarring and congestion is evident.

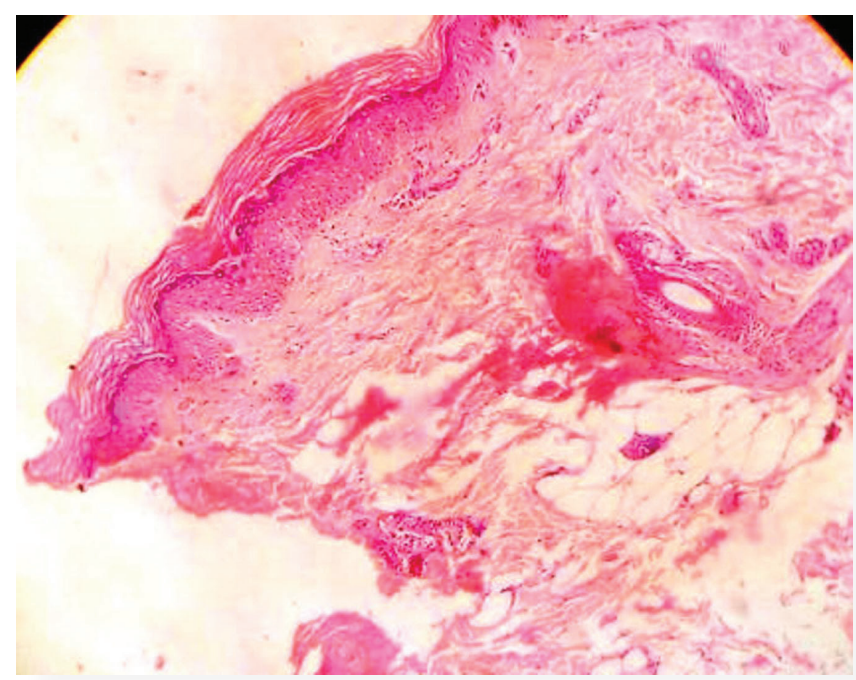

Figure 3. Histopathology of skin under scanner view showing epidermal hyperkeratosis with atrophy of some of the rete ridges and elongation of others. (H\&E, 10x) from the cutaneous lesions. Histopathology of skin showed hyperkeratosis and focal thinning of stratum malphigi with atrophy of some of the rete ridges and elongation of others. Dermis is unremarkable. No evidence of malignancy seen (Figs 3 - 4). The clinical features and that of histopathology were those of photosensitive dermatoses suggestive of Xeroderma Pigmentosum.

The patient was referred to ophthalmology and paediatric specialists for further care and was adviced cutaneous photoprotection with judicious use of sunscreens. The patient and parents were educated about the disease and the importance of skin care and was advised for regular follow-up every six months and to report any new skin lesions appearing suspicious.

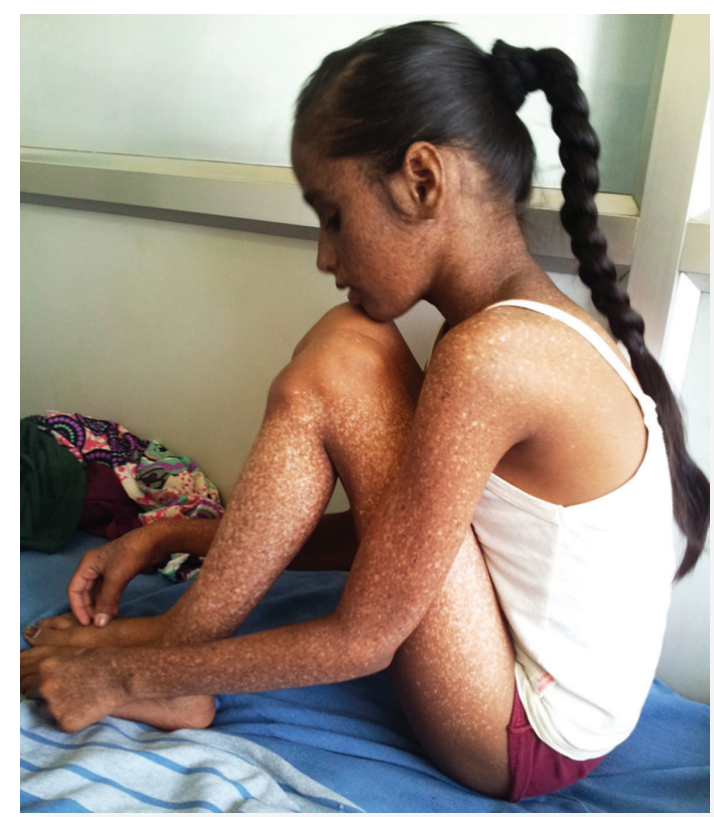

Figure 2. Side view of the child showing diffuse hyperpigmented lentigos and freckles with a mixture of hypopigmented macules over the extremities.

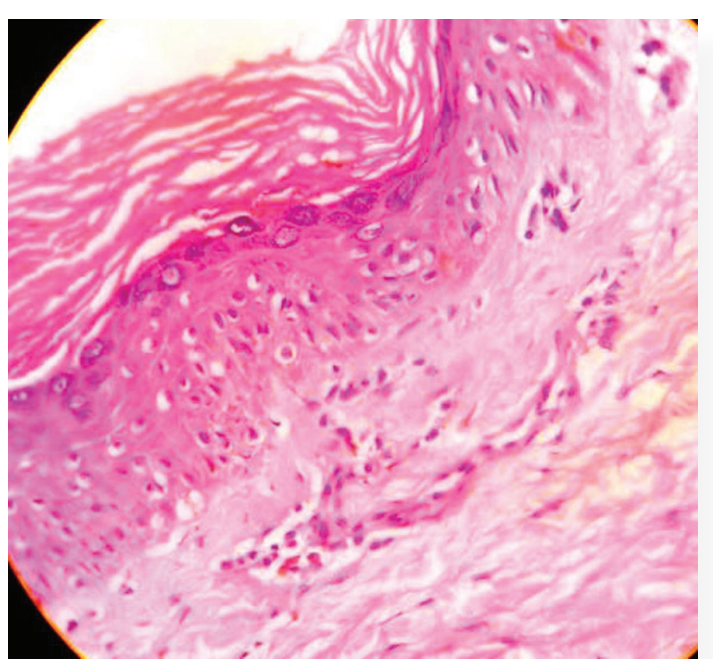

Figure 4. Histopathology of skin under high power view shows hyperkeratosis and focal thinning of stratum malphigi with atrophy of some of the rete ridges and elongation of others. Dermis is unremarkable. No evidence of malignancy seen. (H\&E, 40x) 


\section{Discussion}

Xeroderma Pigmentosum (XP) is a rare genetic disorder that occurs worldwide in all races and ethnic groups. First described by Hebra and Kaposi in 1874, the disorder is characterised by marked photosensitivity and premature onset of all major types of skin cancer [1].

From an early age patients are sensitive to even minimal sun exposure developing erythema, vesicles and oedema. By the age of two years solar lentigos, xerosis and pigmentation occur. Later in childhood dysplastic and neoplastic lesions occur with the development of actinic keratosis, keratocanthoma, basal cell carcinoma, squamous cell carcinoma and malignant melanoma [1]. In one study the median age for development of malignant melanoma was 8 years of age [2]. Ocular complications are nearly as common as skin lesions with keratitis progressing to corneal opacification, loss of eyelashes, ectropion, entropion and benign and malignant lesions of the cornea and eyelids. Neurological complications occur in approximately $30 \%$ of cases and can be severe with developmental delay $[1,5]$.

$\mathrm{XP}$ is usually inherited in an autosomal recessive manner with phenotypically normal heterozygotes. There are at least seven different subtypes (complementation groups A-G) as well as XP variants. Various rare forms occur in combination with other disorders such as Cockayne's Syndrome [1]. 80\% of patients have classical XP where there is a defect in the initiation of DNA nucleotide excision repair after UV induced damage. In $\mathrm{XP}$ variant the defect is found in post-replication or daughterstrand repair [4].

The diagnosis of XP is considered when a young patient presents with marked photosensitivity, xerosis and multiple pigmented lesions. Phototesting may be performed showing reduced minimal erythema dose in the 290 to $340 \mathrm{~nm}$ range [3]. Although phototesting is widely available in the developed world it is neither sensitive or specific for XP. The diagnostic test of choice is time consuming, highly specialised and expensive: cultured fibroblasts are extracted from a skin biopsy, fused with fibroblasts from known XP lines and exposed to UV irradiation. If the subsequent DNA repair is defective, the XP complementation group may be identified from the fused XP line used. Recent developments include the cloning of all XP genes, so the complementation group can also be determined by using recombinant retroviral vectors $[1,2,4]$.

The treatment of XP is challenging because it is a multi-organ and multi-system disease, and because usually by the time of diagnosis, significant tissue damage has already occurred $[1,4]$. Malignant tumours may already have developed by the third or fourth year of life [1]. Early diagnosis and immediate implementation of rigorous sun-protection measures may prolong the lives of persons with XP. About two thirds of unmanaged subjects die before the age of 20 years [1,4], but in climates with intense sunlight exposure, children with XP who do not implement sun-protection measures and have limited access to modern medical care, have a life expectancy of about 10 years [6].

Persons with XP must avoid exposure to any sources of UV light including sunlight, fluorescent, halogen and mercury-vapour lights [5], and must wear protective clothing and UV-absorbing eye glasses, and must use high protection factor sunscreens [1]. $\mathrm{XP}$ associated cutaneous, ocular and oral lesions and dis-orders should be treated as in any other person. Topical application of 5-fluorouracil or imiquimod is appropriate for premalignant and surgical excision for malignant neoplasms of the skin, tongue, eyelids, conjunctiva and cornea. Methyl cellulose or quinodinecontaining eye drops, and bland ointment at night, constitute correct eye-care $[7,8]$. It must be remembered that persons with XP who are properly protected from sun-light may suffer consequential vitamin D deficiency, and they should routinely take vitamin D supplements [2]. Treatment modalities for XP include Isotretinoin prophylaxis, avoidance of light exposure, surgical excision of pre malignant and malignant tumors, resurfacing with skin grafts, dermabrasion, radiation therapy, and Mohs micrographic surgery $[9,10]$. Experimental treatments with topical DNA repair enzymes and oral retinoids are showing promise for the future [11,12].

There are particular challenges when a child with XP grows up in a tropical environment as illustrated in this case. The geographical and cultural bars to medical facilities led to a significant delay in diagnosis for this patient. This has resulted in years of photodamage resulting in the patients striking appearance with cutaneous and ocular damage and undoubted limited lifespan. Culturally the patient would have spent most of the day outdoors in the equatorial high UV exposure environment. Even if a medical opinion was sought earlier in life we must consider the lack of specialists and the high cost of the specialized diagnostic tests needed.

\section{REFERENCES}

1. Harper JI. Genetics and genodermatoses. In: Champion RH, Burton JL, Burns DA, et al. eds. Rook, Wilkenson, Ebling Text-book of Dermatology. 6th edition. Oxford: Blackwell Science Ltd 1998, pp. 357 436

2. Kraemer KH, Lee MM, Scotto J. Xeroderma Pigmentosum: cutaneous, ocular and neurological abnormalities in 830 published cases. Arch Dermatol. 1987;123:241-50.

3. Ramsay CA, Giannelli F. The erythemal action spectrum and deoxyribonucleic acid repair synthesis in xeroderma pigmentosum. $\mathrm{Br} \mathrm{J}$ Dermatol. 1975;92:49-56.

4. Rünger TM, DiGiovanna JJ, Kraemer KH. Hereditary disorders of genome instability and DNA repair. In:Wolff K, Gold-smith LA, Katz SI, et al. Fitzpatrick's dermatology in general medicine. 7th edition. New York: McGraw Hill Co 2008, pp.1311-25.

5. Halpern J, Hopping B, Brostoff JM. Photosensitivity, corneal scaring and developmental delay: Xeroderma pigmentosum in a tropical country. Cases J. 2008;1:254.

6. Cleaver JE, Revet I. Clinical implications of the basic defects in Cockayne syndrome and xeroderma pigmentosum and the DNA lesions responsible for cancer, neurodegeneration and aging. Mech Ageing Develop. 2008;129:492-7.

7. Mahindra P, DiGiovanna JJ, Tamura D, Brahim JS, Hornyak TJ, Stern $\mathrm{JB}$, et al. Skin cancers, blindness, and anterior tongue mass in African brothers. J Am Acad Dermatol. 2008;59:881-6.

8. Goyal JL, Rao VA, Srinivasan R, Agrawal K. Oculocutaneous manifestations in xeroderma pigmentosa. Br J Ophthalmol. 1994;78:2957.

9. Agrawal K, Veliath AJ, Mishra S, Panda KN. Xeroderma Pigmentosum: Resurfacing Versus Dermabrasion, Br J Plast Surg. 1992;45:311-4.

10. Leal-Khouri S, Hruza GJ, Hruza LL, Martin AG. Management of a Young Patient with Xeroderma Pigmentosum. Pediatr Dermatol. 1994; $11: 72-5$

11. Kraemer KH, DiGiovanna JJ, Moshell AN, Tarone RE, Peck GL. Prevention of skin cancer in xeroderma Pigmentosum with the use of oral isotretinoin. N Engl J Med. 1988;319:1633-7.

12. Yarosh D, Klein J, O'Connor A, Hawk J, Rafal E, Wolf P. Effects of topically applied T4 endonuclease $\mathrm{V}$ in liposomes on skin cancer in xeroderma pigmentosum: a randomised study. Xeroderma pigmentosum study group. Lancet. 2001;357:926-9

\footnotetext{
Copyright by Hari Kishan Kumar Yadalla, et al. This is an open access article distributed under the terms of the Creative Commons Attribution
} License, which permits unrestricted use, distribution, and reproduction in any medium, provided the original author and source are credited. 